\title{
When Does Quality of Life Improve After Liver Transplantation? A Longitudinal Prospective Study
}

\author{
D. Telles-Correia, A. Barbosa, I. Mega, E. Mateus, and E. Monteiro
}

\begin{abstract}
Objectives. We sought to investigate the improvement in quality of life (mental and physical components) at 1 and 6 months after liver transplantation.

Methods. A sample of liver transplant candidates $(n=60)$, comprising consecutive patients attending outpatient clinics of a liver transplantation central unit $(25 \%$ of the patients had familial amyloid polyneuropathy [FAP] and the remaining patents had chronic liver diseases), was assessed by means of the Short Form (SF)-36, Portuguesevalidated version, a self-rating questionnaire developed by the Medical Outcome Trust, to investigate certain primary aspects of quality of life, at 3 times: before, and at 1 and 6 months after transplantation.

Results. We observed a significant improvement in quality of life (both mental and physical components) by 1 month after transplantation. Between the first month and the sixth month after transplantation, there also was an improvement in the quality of life (both mental and physical components), although only the physical components of quality of life was significantly improved.

Conclusions. Our findings suggested that quality of life improved early after liver transplantation (1 month). Between the first and the sixth months, there only was a significant improvement in the physical quality of life.
\end{abstract}

$\mathrm{N}$ OWADAYS, THE CALL to examine quality of life as it is affected by transplantation has became stronger, because transplantation technology and immunosuppression have lead to many kinds of transplants. The increasing prevalence of transplantation demands full consideration of the range of costs and benefits. Most studies have demonstrated that quality of life is improved by transplantation of patients with liver disease..$^{1-4}$ Nevertheless, many authors debate when the improvement occurs. Most studies assess patients more than 6 months after transplantation. In contrast, the few studies that evaluate patient quality of life during the first months after transplantation report contradictory results, sometimes showing worsened patient quality of life (mental or physical dimensions). ${ }^{5}$ The present study sought to investigate the improvement in quality of life (mental and physical components) at 1 and 6 months after liver transplantation.

\section{METHODS}

Participants

We studied a sample of transplant patients $(n=60)$, composed of consecutive patients with paramyloidosis, alcoholic cirrhosis, and

0041-1345/09/\$-see front matter doi:10.1016/j.transproceed.2009.01.051 other liver diseases, attending our weekly outpatient clinics between March 1, 2006, and March 1, 2007. All participants agreed to participating in the study after informed consent. The study protocol was approved by the institutional review committee (according to ethical guidelines of the 1975 Declaration of Helsinki). We assessed these patients before and 1 and 6 months after transplantation.

\section{Measurement of Quality of Life}

We used the Short Form (SF)-36 (Portuguese-validated version), a self-rating questionnaire developed by the Medical Outcome Trust $^{6}$ to investigate certain primary aspects of quality of life. The SF-36 has been widely used under a range of medical conditions. It has been shown to have adequate reliability and validity. The first 4 subscales refer to physical aspects; the last 4 subscales, mental aspects: namely, physical functioning, physical role limitation,

From the Psychiatric Approach to Liver Transplanted Patients' Unit, Curry Cabral Hospital's Liver Transplantation Center, and the Lisbon Faculty of Medicine, Lisbon, Portugal.

Address reprint requests to $\mathrm{Dr}$ Diogo Telles-Correia, Rua Sacadura Cabral $n^{\circ}$ 55, 4 B, 1495 Cruz Quebrada-Dafundo, Portugal. E-mail: tellesdiogo@gmail.com 360 Park Avenue South, New York, NY 10010-1710 
Table 1. Medical Diagnosis-Subgroups

\begin{tabular}{lc}
\hline \multicolumn{1}{c}{ Medical Diagnosis } & $n$ \\
\hline Familial amyloid polyneuropathy & 15 \\
Chronic liver diseases & \\
Alcohol liver disease & 13 \\
Hepatitis C-associated cirrhosis & 7 \\
Hepatocellular carcinoma & 2 \\
Primary biliary cirrhosis & 2 \\
Familial progressive cholestasis & 1 \\
Mixed diagnosis & 18 \\
Unknown cause & 2 \\
\hline
\end{tabular}

Note. A total of 60 cases were included.

bodily pain, general health, vitality, social functioning, emotional role limitation, and emotional well-being. Physical aspects mostly refer to the ability to perform normal daily activities. The mental dimension mostly refers to social aspects of life and the degree to which the illness interferes with emotional well-being and social roles. Total values were computed for physical and mental components of health-related quality of life by averaging the 8 weighted subscales using the coefficients generated by Hays et $\mathrm{al}^{7}$ in the Medical Outcomes Study. We measured quality of life at 3 times: before as well as at 1 and 6 months after transplantation.

\section{Statistical Analysis}

Statistical analyses were performed with the SPSS 13.0 for Windows software package. Descriptive data were presented in frequencies. Evaluation of differences in quality of life were performed using paired samples Student $t$-test.

\section{RESULTS}

\section{Demographic and Medical Data}

Regarding the medical diagnosis, 15 patients had familial amyloid polyneuropathy (FAP) and 45 had chronic liver disease (CLD). Among the patients with chronic liver disease, 13 had alcoholic liver disease (ALD); 7, hepatitis C associated cirrhosis (HCAC); 2, hepatocellular carcinoma (HCC); 2, primary biliary cirrhosis; 1, familial progressive cholestasis; and the others mixed diagnoses (7, ALD+HCC; 7, $\mathrm{HCAC}+\mathrm{HCC} ; 2, \mathrm{HCAC}+\mathrm{HCC}+\mathrm{ALD} ; 1, \mathrm{HCC}+$ virus $\mathrm{B}$ liver disease; 1 , hemochromatosis $+\mathrm{LC}$ ), and 2 unknown cause (Table 1).

\section{Quality of Life Evolution}

We observed a significant improvement $(P<.001)$ in quality of life (both mental and physical components) at 1 month after transplantation. Between the first and the sixth months after transplantation, only the physical quality of life showed a significant improvement $(P<.05)$ (Tables 2 and 3$)$.

Table 2. Differences Between Quality of Life Before and at 1 Month After Liver Transplantation

\begin{tabular}{lcccc}
\hline $\begin{array}{c}\text { Component } \\
\text { Quality of Life }\end{array}$ & $\begin{array}{c}\text { Before } \\
\text { Transplantation }\end{array}$ & $\begin{array}{c}\text { 1 Month After } \\
\text { Transplantation }\end{array}$ & $t$ & $P$ \\
\hline Mental & 49.87 & 63.96 & -4.412 & .000 \\
Physical & 47.91 & 57.08 & -2.823 & .007 \\
\hline
\end{tabular}

Table 3. Differences Between 1 and 6 Months After Transplantation

\begin{tabular}{lcccc}
\hline $\begin{array}{l}\text { Component of } \\
\text { Quality of Life }\end{array}$ & $\begin{array}{c}\text { 1 Month After } \\
\text { Transplantation }\end{array}$ & $\begin{array}{c}\text { 6 Months After } \\
\text { Transplantation }\end{array}$ & $t$ & $P$ \\
\hline Mental & 63.96 & 65.02 & -.179 & .859 \\
Physical & 57.08 & 64.22 & -2.823 & .030 \\
\hline
\end{tabular}

\section{DISCUSSION}

This is one of the few studies to investigate quality of life before 6 months after liver transplantation. Our findings suggested that mental and physical components of quality of life improved early after liver transplantation (1 month). At 6 months, only the physical component of quality of life showed further improvement. We did not find any literature about the timing of improvements in quality of life after transplantation. Although some works measured quality of life at more than 1 time after transplantation, a comparison between these times was not made. Nevertheless, we did find in the literature some studies that suggested that quality of life improvement was mostly seen in the first months after transplantation, and that there could be a decreased quality of life thereafter. ${ }^{8}$

The reason why the mental component of quality of life failed to improve after the first months may be related to various factors: the great expectations that patients have toward transplantation (perhaps not corresponding to reality); the perception that they are "not cured" after transplantation and still have to take medication and be followed by a doctor; and the kind of medication that these patients take (usually corticosteroids are taken in the first months after transplantation). Further studies are needed to confirm these hypotheses. Knowledge about how and when quality of life improves after liver transplantation may be useful for future interventions that optimize the quality of life of these patients.

\section{REFERENCES}

1. Tarter RE, Switala J, Arria A, et al: Quality of life before and after orthopic hepatic transplantation. Arch Intern Med 151:1521, 1991

2. Moore KA, Jones R, Angus MCL, et al: Psychosocial adjustment to illness: quality of life following liver transplantation. Transplant Proc 24:2257, 1992

3. Riether AM, Smith SL, Lewison BJ, et al: Quality of life changes and psychiatric and neurocognitive outcome after heart and liver transplantation. Transplantation 54:444, 1992

4. Price CE, Lowe D, Cohen AT, et al: Prospective study of the quality of life in patients assessed for liver transplantation: outcome in transplanted and not transplanted groups. J R Soc Med 88:130, 1995

5. Hicks FD, Larson JL, Ferrans CE: Quality of life after liver transplantation. Res Nurs Health 15:111, 1992

6. Ware J: SF-36 Health Survey: Manual and interpretation guide. Boston: Nimrod; 1993

7. Development of the Portuguese version of MOS SF-36. Part II-validation tests. Acta Med Port 13:119, 2000

8. Price CE, Lowe D, Cohen AT: Prospective study of the quality of lifein patients assessed for liver transplantation: outcome in transplanted and not transplanted groups. J R Soc 88:130, 1995 